\title{
REGISTRO BIBLIOGRÁFICO
}

\author{
Manoel de Oliveira Franco Sobrinho - ESTRUTURA POLí- \\ TICA DO MUNDO MODERNO - livro ainda inédito - \\ critica e apresentação de Arthur Cezar Ferreira Reis.
}

A literatura brasileira, visando ao estudo do processo político universal, de que somos um reflexo natural, não se enriquecéu ainda pela variedade das interpretações ou pela objetividade das investigações $\in$ ' reflexões. É mesmo, a certos aspectos, uma literatura pobre, que só muito recentemente provocou algum interesse dando margem ao aparecimento de especialistas. Especialistas, diga-se logo, libertos do jurisdicismo a qué viviamos atrelados, confundindo ciência política com exercício de direitos e obrigações fixados em código e leis. $O$ ensino do direito, como iluminismo a século XVIII, embora aparecendo no século $X I X$, foi, de certo aspecto, impeditivo de que nos preocupássemos com a ciência política, aue não se diga que é ciência muito atual, pois que deita suas raízes em épocas muito distantes da nossa.

A leitura de Bagheot, por exemplo, foi moda. Joaquim Nabuco encontrou no livro do mestre britânico os fundamentos para suas razões políticas quando teve de enfrentar as reações e o conservadorismo dos homens que detinham o poder em nossa Pátria e não queriam progredir face às mudariças que já se processavam com certa intensidade no mundo de que éramos parte solidária. Constituiu mesmo uma exceção. Os pensadores políticos nacionais, da estatura de um Tavares Bastos e poucos, pouquíssimos outros, a contarmos nos dedos das duas mãos somadas, pouca influência, por isso mesmo, provocaram no particular da utilização do que a ciência política ensinava e era necessário para as soluções da gigantesca problemática que nos atormentava e para a oual poucos remédios estávamos encon trando. Os livros interessantíssimos de Alberto Sales pouco produziram, despertando mesmo curiosidade. Como a obra de Alberto Torres, só hoje avaliada no que representou como contribuição face a análise da vida nacional.

Quando se escrever a história do pensamento político brasileiro, verificaremos a pobreza franciscana que nos caracterizou nesse particular da inteligência criadora $O$ esforço, portanto, dos que, em 
Minas Gerais, na Universidade Federal de Belo Horizonte, ou no Centro, mantido na Fundação Getulio Vargas, estão realizando para que a ciência política seja uma realidade, cogitada nos curriculum universitários e divulgada nos livros, ensaios e monografias que lançam, é um esforço admirável, quase diríamos revolucionário. $E$, no entanto, se olharmos o que se faz nos Estados Unidos ou, para ficar mais perto na própria Argentina, onde a tradição dos pensadores políticos começa nos albores da luta pela soberania nacional, ainda nos inícios do século XIX, que diferença, que distância! Não se alegue, que em nenhum momento estivemos fora da área de influência das transformações ideológicas que marcaram os momentos históricos. Recebemos essa i n f I u ê n c i a, servimo-nos dela, incorporamo-la ao nosso patrimônio de experiência para o exercício de nossa atividade institucional, mas desprezamos sempre a análise das doutrinas, das idéias, das reflexões que os pensadores políticos lançavam a serviço da renovação mundial. Sucedeu o mesmo com relação à filosofia. Ao lermos, por isso, os ensaios de João Cruz Costa e Antonio Paim, ou de Guilhermo Francovich e Antonio Gomes Robledo, espantamo-nos com a revelação, que nos fazem, de que houve espíritos lúcidos que se preocuparam com os problemas filosóficos sem se haverem constituído em meros divulgadores do pensamento exterior. Seria a raiz portuguesa a responsável por essa ausência brasileira? Não se acusa o homem ibérico de estranho a esse gênero de especulação, dé mais pragmático na essência de sua vida e de suas cogitações? Não é essa tese defendida por muitos que explicam, desse modo, um tanto simplista, a contribuição escassa de portugueses e espanhóis, de portugueses principalmente? O Instituto de Cultura Portuguesa, que Adriano Moreira dirige, preocupa-se, no momento, justamente com esse tipo de indagação e de inventário, passo inicial para uma resposta austera, serena, segura às indagações que todos nós fazemos para explicar-nos em muitas de nossas peculiaridades e de nossas atitudes já se divulgam os primeiros textos a comprovarem a existência de pensadores políticos na Idade Média e nos tempos do Renascimento, para cujo adverito e progresso tanto os portugueses contribuiram com a incorporação de humanidades, espaços físicos, naturezas, particularidades novas de mundos estranhos que descobriam e investigavam, ao mesmo tempo em que se faziam os autores da primeira etapa da europeisação da terra, o que vale dizer claramente, do domínio da Europa sobre povos e continentes exóticos.

Todas essas reflexões nos vêm a propósito do livro que prefaciamos, de autoria do professor Manoel de Oliveira Franco Sobrinho. Escrevendo sobre a "Estrutura Política do Mundo Moderno" tenta o ensaio acerca do pensamento político à luz da ciência e das experiências que essa ciência está provocando por toda parte. Porque nesse 
livro, cheio do maior interesse, quase que um livro de excepcional importância pelas novidades que registra e pela informação atualizadíssima que nele se contém sobre a vida política e o pensamento político de nossos dias, há não apenas a divulgação de toda essa ciência política, aplicada em continente e sobre povos os mais diversificados em seus graus de cultura material e espiritual, mas a idéia própria de um pensador político que é o proféssor Franco Sobrinho.

Estamos vivendo dias de transformações súbitas, profundas, nu. ma inquietação que não permite ver o futuro. Há um mundo que se altera em sua estrutura física e em sua estrutura humana. $O$ advento de novas nacionalidades, ao lado de velhos povos que se modificam também para integrar-se no realismo dos tempos atuais, constituem um campo admirável para a observação científica no particular das doutrinas e das aplicações da ciência política. Estilos antigos e estilos mais atualizados sofrem a confrontação da experiência diária. Insista-se na tese-povos de ontem e povos de hoje, num afã intensificado diariamente, procuram seus destinos, vencendo crises e destruindo mitos, afirmativas ultrapassadas. tentando a elaboração de uma huma nidade e de uma sociedade universal que se defina com menos brutalidade e seja mais afirmada pela posse do instrumental útil à sobrevivência da espécie humana e, com essa sobrevivência, a cons. trução de um mundo menos áspero, mais sensível.

As fórmulas que serviram para a sustentação dé impérios, de nações fortes, poderosas, dominadoras, são fórmulas que já não contam mais com a aceitação passiva, porque tivessem sido fórmulas, se não salvadoras, fórmulas que asseguraram vitalidade, crescimento, progresso. Não se diga que esse será um tormento que vivem as nações jovens, em sua primeira fase de vida soberana, portanto indecisas ou desconfiadas daquele contexto formal que serviu para contêlas em seus desejos de liberdade ou de bem-estar. Encontramos o mesmo estado de espírito, a mesma indecisão, a mesma dúvida e incerteza nas nações mais idosas, mais autenticamente experientes, com raízes num passado antiquíssimo, que lhes serviu para a destinação que foram alcançando e seria o fruto justamente de toda essa disciplina a que se submeteram, mas já lhes parece também sem conteudo que thes valha para a dinâmica de hoje.

Em seu livro síntese do pensamento político, nas variadas aplicações que vem tendo nas nações novas e nas nações mais idosas, o professor Franco Sobrinho passa em revista o que está ocorrendo na Europa em renovação intensa e nas Américas, prometendo a verificação mais demorada, em volume posterior, acerca do que sucede na Africa e na Asia, o que não significa que tenha ignorados muitos aspectos dessa atividade política para as comparações e para a exege- 
se que faz de todo o processo de governo, seja o democrático clássico, seja o das linhas marxistas, do socialismo, veiculado por Moscou, por Pequim ou por Havana.

Sustentando, como é certo, que o Estado motor, o Estado realizador, condutor, controlador, coordenador, todo poderoso, está dando lugar em toda parte ao velho Estado liberal do século XIX, ensina: "vingou a tese que atemoriza do executivo-forte. Na realidade, sejam outras ou essas as conveniências, o mundo moderno exig'e força, no procedimento da ação política. O exemplo éstá na maioria das cartas atuais, inclusive e principalmente nas cartas das nações socialistas e socializadas".

Examinando o caso particular do Brasil, compreende, no realismo que seria de desejar, face a um contexto de circunstâncias peculiaríssimas nossas, tendo-se em consideração as etnias de nossa formação, o espaço físico, o processo histórico, os impulsos que nos distinguem, nossas características como povo e como sociedade política, nossa tão crua situação cultural, compréende-nos como somos e conseqüentemente como devemos ser conduzidos. E lembrando Alberto Torres, quando o pensador afirmava que uma nação não é uma obra artificial, nem artificiosa, surge quando nasce, não pode, para sobreviver, usar roupagem de empréstimo, escreve: "9l organizou, se organização pôde trazer, ou pretendeu organizar, a desordem institucional vinda da Colônia através do Império. Não formou, porém, nem de longe, um senso dinâmico da vida política. Acompanhasse Torres a projeção no tempo veria o asserto da uva afirmativa quando conceituava que a "desorganização política destroi uma nação mais do que as guerras". Em serviço de formas de governo e das doutrinas que tem adotado, - Brasil não conseguiu burlar a história sofrendo exceções que abalaram a fragilidade das instituições sem arcabouço. A organização política e administrativa do País ainda está a espera de orgyanização. 1934 foi outra tentativa fracassada de estética constitucional e de ideal político. 1937 escreveu-se para não cumprir e nem executar, não e'squecendo que as regras impostas não asseguraram permanência constitucional. 1946 repetiu as extravagâncias de 1891 procurando a uniformidade no que era disforme e distorcendo assim o desenvolvimento verdadeiro e positivo da vida política. 1967, ainda que pareça milag're, e'stá procurando fugir às formas abstratas convencionais. A superioridade do ante-projeto sobre a carła votada é evidente. Em verdade, no entanto, instalou um regime constitucional menos ostensivo e mais verdadeiro para conciliar a réalidade com a abstração. Torres já esperava isso em 1914".

Depois de uma análise profunda de toda a evolução política do 
Brasil, nas experiências de governo e de sistemas que já viveu, detém-se na carta em vigor. Tem a coragem de compreendê-la dentro daquela realidade gritantemente áspera que Alberto Torres denunciára, mas não encontrara eco. Carta elaborada para um Brasil como ele é e não como desejariamos que já fosse, portanto um Brasil de desequilíbrios regionais violentos, de condições culturais as mais variadas e disitintas, de economia predatória em algumas áreas e de economia de alto teor de potencialidade em outras, de sociedade diversificada por intensa politização aqui e imaturidade ali, Brasil velho e Brasil novo, dois Brasis, como descobriram Roger Bastide e Jacques Lambert, Brasil dinâmico e Brasil sem velocidade, o diploma de 1967 é proposto nos objetivos por que foi redigido, objetivos decorrentes do quadro existente e não o quadro aspirado, perseguido e ainda não composto pelo homem em seu esforço de perfeição e na angústia de uma potencialidade que será o futuro, mas não é o hoje. A propósito afirma: "o poder político ficou pois assim um só impondo incondicionalmente autoridade capaz de manter a ordem constituída e a tranquilidade social".

Com uma coragem que merece ser assinalada numa época em que muitos se acomodam e não sabem defender o próprio pensamento, o professor Franco Sobrinho, que é também magistrado, sustenta a excelência do diploma, lembrando que a experiência de um texto legal não se pode fazer sem que o tempo exerça o seu papel crítico.

O Estado forte, como o Executivo forte, é característica dos tempos novos que estamos realizando com a nossa presença no cenário terreno e nosso comportamento, criando instituições, exercendo o direito de viver, tentando elaborar aquela sociedade que não pertença apenas a alguns, mas seja pałrïmônio comum a todos. No livro do professor Franco Sobrinho há uma admirável correção de propósitos didáticos ao mesmo tempo que uma contribuição excelente para o entendimento da natureza humana nas suas experiências políticas, em particular as que são o condicionamento de nossa atualidade.

\section{ARTHUR CEZAR FERREIRA REIS}

Presidente do Conselho Federal de Cultura. 